\title{
The effectiveness of a coping- focused prevention approach: A two-year longitudinal study
} Guy Bodenmann, Meinrad Perrez, Annette Cina and Kathrin Widmer

University of Fribourg, Switzerland

This article focuses upon a new preventive approach designed to improve personal stress management skills. The Coping Enhancement Training (CET) is derived from the Couples Coping Enhancement Training (CCET) and encompasses both an individual and a dyadic aspect. In this study, only the individual element is described. The training is based upon the transactional stress concepts of Lazarus and his coworkers and the further development of this approach by Perrez and Reicherts (1992). Personal coping skills are practiced over a six-hour period by means of theoretical, diagnostic and practical work. This article presents the rationale and content of the program, as well as data concerning the effectiveness of this approach after a period of two years.

The data shows that subjects participating in the program displayed better individual coping skills (e.g. active problem-solving and positive self-verbalization) after the training and that they relied upon dysfunctional coping strategies (e.g. rumination and blaming strategies) less often even after two years.

Keywords: Stress, coping, marriage, prevention, effectiveness

Stress prevention has come to play a significant role in the arena of mental health. In recent years, an increasing amount of stress prevention training programs has been introduced and a wealth of self-help literature on the theme of stress has been written. The majority of these stress prevention programs focus upon improving fundamental competencies in dealing with stress issues (i.e., actively influencing the situation, cognitive restructuring etc.) and upon modifying physiological reactions to stress through emotion and relaxation-oriented intervention strategies (e.g. relaxation techniques, distraction, reframing of the situation etc.).

These two main goals, namely the enhancement of problem-focused and emotion-focused coping, have traditionally been addressed as they play a significant role in the transactional stress model of Lazarus (e.g. Lazarus, 1993; Lazarus \& Folkman, 1984; Lazarus \& Launier, 1978). Based on this approach, most programs use traditional, psycho-educational techniques (e.g., dissemination of relevant information, problem-awareness training, im- provement strategies) and cognitive and behavioral therapy techniques (i.e., agenda planning, time management skills, cognitive restructuring, self-instruction, problemsolving skills, relaxation techniques) (see Schröder, 1996).

Nevertheless, we would suggest that the frequent lack of empirical data provided by these stress prevention programs is of critical concern considering their widespread use. In addition, the meta-analyses of Canella (1988) and Nicholson, Duncan, Hawkins, Belcastro, and Gold (1988) provide no conclusive indication as to the effectiveness of current stress prevention programs since in both cases these studies included not only prevention programs but also therapies. In Germany, Bamberg, and Busch (1996) have offered a primary prevention meta-analysis concerning the effectiveness of stress prevention programs in the work place. In addition, Kaluza (1997) has provided a meta-analytic evaluation of a primary prevention program. The average rate of effectiveness for these programs lies between $d=.20$ and .50. The most significant effects were linked to Type A behavior and psychological factors. 
Little or no improvement with regard to stress awareness and physical factors was found. What is more, there was insufficient evidence showing a significant improvement in the relevant coping skills (see Kaluza, 1997).

In the following study, we will show the effectiveness of a primary prevention program for coping with stress that entails the following four intervention components: a) an improvement in the appraisal and interpretation of stressful situations, b) an enhancement of individual coping skills, c) an increase in stress defeating activities (hedonistic repertoire), and d) strengthening an awareness of the importance of choosing situation-appropriate coping strategies. A change in individual coping over a period of two years following participation in the training was designated as the dependent variable in the study. It was hypothesized that those individuals who participated in the program would, after the training, be better able to cope with stress and would rely less frequently on dysfunctional coping strategies than would those individuals from the control groups.

\section{The Coping Enhancement Training (CET)}

The CET is empirically based upon stress research and is drawn from the transactional approach of Lazarus and Launier (1978) and the further development of this approach by Perrez and Reicherts (1992). Six hours are devoted to the development of individual coping competencies. This section represents two units of the larger Couples Coping Enhancement Training (CCET; Bodenmann, 1997; Bodenmann, Charvoz, Cina, \& Widmer, 2001), which addresses in addition to this individual aspect the enhancement of marital competencies such as dyadic coping, marital communication and dyadic problem-solving (that part of the training oriented toward dyadic coping will not be presented here). The program is structured in a modular fashion in accordance with the behavioral modification theories of Maccoby and Solomon (1981) (e.g., problem awareness, motivation, improvement of skills, maintenance of learned competencies). In addition to theoretical inputs, the training includes intensive and supervised exercises, role-playing and home work.

Unit 1: The first unit of the training entails an introduction to the program itself. The source of stress and the different types of stress and their consequences are then discussed. Next, the role that our subjective appraisal plays in how we understand situations and their stressful potential is addressed, as is the role that feelings (fear, sadness, anger etc.) play in our interpretation of a situation (e.g. as threatening, damaging, demanding). Specific practical examples are offered to clarify this important issue. The participants are then asked to analyze their own stress level in different areas of their life and to ascertain which coping strategies have worked for which situation. The goal of this unit is to strengthen a) the accuracy of appraisals regarding the situation (concerning specific features such as controllability of the situation, ambiguity, changeability, certainty), b) to improve the understanding that different kinds of situations demand different coping strategies that are matched to the specific features of the situation, as well as c) to show subjects that stress feelings are consequences of these appraisal processes (see Weiner, 1982).

The intervention in this unit occurs in the form of theoretical inputs (lectures) and systematic illustrations using both examples and exercises to show that how one experiences a stressful situation is dependent upon one's own subjective evaluation.

Unit 2: In the second unit of the program, the main strategies that may be used to individually cope with stressful encounters are presented such as a) the avoidance of unnecessary stress (through improved planning, adequate organization, the ability to compromise, setting boundaries etc.), b) the incorporation of regenerative activities incompatible with stress (enjoyable and rejuvenating activities etc.) in everyday life, c) the improvement of the accuracy of appraisals and d) the enhancement of effective and functional coping strategies as well as a decrease in the use of strategies that would prove inappropriate to the situation. Additionally, a relaxation technique (see Jacobson, 1938) is taught.

In accordance with the above-mentioned transactional model, emotion-focused and problem-oriented intervention coping strategies are taught. Subjects are encouraged actively to influence the situation, to utilize anticipatory strategies (prevention and avoidance of stress) as well as to build a pool of pleasant and regenerative activities. The anti-stress activities proposed (hedonistic repertoire) are based upon the daily up-lifts presented in the work of Kanner, Coyne, Schaefer, and Lazarus (1981), Koppenhoefer (1990) and Lazarus (1986). The goals of this unit are the improvement of individual coping skills on all levels, the amelioration of appraisal accuracy (i.e., the ability to classify situations based upon objective criteria), the ability to apply situation-appropriate coping strategies and an increased recognition that a hedonistic repertoire is both efficient in reducing stress and can act as a prevention to stress on a long term basis. In order to reach these goals, the techniques applied are primarily cognitive (e.g., problem and situation analyses, planning of concrete activities, self-observation, time management, daily planning, cognitive restructuring, self instruction technique as well as 
progressive muscle relaxation) in accordance with cognitive-behavioral methods proposed by Beck, Rush, Shaw, and Emery (1979), Bodenmann (2000), D'Zurilla and Goldfried (1971), Meichenbaum (1991) and Perrez and Reicherts (1992).

The training was carried out by graduate students in clinical psychology in their last semester and by psychologists without clinical-therapeutic experience. The trainers participated in a four-day-long theoretical and practical training session and completed approximately 20 hours of group supervision. Supervision meetings with the trainers were held on a regular basis throughout the entire study.

\section{Method}

\section{Subjects}

Pre-training data for CET was collected initially for 330 subjects. In the analyses presented in this article only those participants who completed all questionnaires during the data collection periods over two years were counted in the final analysis, namely 146 participants in the intervention group (73 couples) and 140 in the control group (70 couples). There was a drop-out rate of $13.1 \%$ in the intervention group and of $13.6 \%$ in control group (11 couples each). Demographic data for both samples is listed in Table 1.

The subjects from the intervention and the control groups did not differ in important demographic variables except age; in this case the controls were older, $t(141)=$ $-3.77, p<.03$.

The participants were recruited by means of advertisements and public flyers. Questionnaires were sent by mail to the participants at each point of the data collection process. The financial cost for each participant to take part in the program was 100 US dollars. Due to the fact that those individuals who applied for the training did so out

Table 1

Demographics of the sample at the beginning of the study

\begin{tabular}{|c|c|c|c|c|}
\hline & \multicolumn{2}{|c|}{ Intervention group } & \multicolumn{2}{|c|}{ Control group } \\
\hline & $\begin{array}{c}\text { Women } \\
(N=73)\end{array}$ & $\begin{array}{c}\text { Men } \\
(N=73)\end{array}$ & $\begin{array}{c}\text { Women } \\
(N=70)\end{array}$ & $\begin{array}{c}\text { Men } \\
(N=70)\end{array}$ \\
\hline Age: $M$ & 39.4 & 41.6 & 43.3 & 45.3 \\
\hline Age: $S D$ & 7.5 & 7.4 & 10.1 & 11.0 \\
\hline Age: Range & $22-58$ & $25-60$ & $25-75$ & $26-76$ \\
\hline Married & $72.3 \%$ & $74.9 \%$ & $79.7 \%$ & $81.4 \%$ \\
\hline Common household & $91.4 \%$ & $93.0 \%$ & $92.6 \%$ & $87.9 \%$ \\
\hline Having children & $72.6 \%$ & $76.7 \%$ & $84.3 \%$ & $80.0 \%$ \\
\hline Elementary school & $11.3 \%$ & $1.5 \%$ & $13.8 \%$ & $9.5 \%$ \\
\hline High school & $33.8 \%$ & $35.3 \%$ & $44.6 \%$ & $31.7 \%$ \\
\hline College & $29.6 \%$ & $19.1 \%$ & $27.7 \%$ & $19.0 \%$ \\
\hline University & $25.4 \%$ & $44.1 \%$ & $13.8 \%$ & $39.7 \%$ \\
\hline
\end{tabular}

of a personal interest in the subject matter, a randomized distribution into program groups was not possible. Consequently, this study is considered to adhere to a quasiexperimental format. Due to the fact that a waiting list control group over a period of two years was not possible, an untreated control group was used.

\section{Procedure}

The effectiveness of the program was tested in a two-year longitudinal study. The following data reported here includes baseline data (two weeks prior to training) as well as data from the follow-up after two years. Data for the follow-ups after two weeks, six months and one year have been reported previously (e.g., Bodenmann, Charvoz et al., 2001; Bodenmann, Perrez, Cina, \& Widmer, 2001).

\section{Questionnaire}

Individual Coping Questionnaire (INCOPE). The INCOPE was developed by Bodenmann (2000) and is based upon the questionnaire (SVF) devised by Janke, Erdmann, and Kallus (1985), as well as the coping categories proposed by Perrez and Reicherts (1992). It is comprised of 21 items pertaining to individual coping. Items are administered on a 5-point Likert scale from 1 (never) to 5 (very often). The questionnaire includes both functional and dysfunctional forms of coping and consists of six factors (positive self-verbalization, problem-solving, rumination, expression of negative emotions, negative palliation and avoidance/withdrawal).

Functional coping strategies include positive palliation (relaxation, positive self-verbalization), information seeking (conscious handling of the problem through increased understanding of the situation), reframing the situation (reappraisal of the situation by viewing it from a different angle), actively influencing the problem, seeking social support and positive self-verbalization. Dysfunctional coping strategies include information suppression (ignoring, disregard of information), negative palliation such as smoking and alcohol consumption, rumination (brooding, obsessive, circular thinking about a situation), avoidance (repressing the problem, ignoring the problem), blaming (self-blaming, blaming the partner or others), comparing oneself to others, emotion-focused information seeking (thinking too much about one's feelings), negative emotional expression (sharing one's feelings without regard to others). The Cronbach Alpha for the entire scale was $\alpha=.72$. The subscales of functional and dysfunctional individual coping showed an internal consistency of $\alpha=.71$ and $\alpha=.70$ respectively. Although the questionnaire has been effectively used in other studies, it has not been validated in relation to other questionnaires (see Bodenmann, 2000). 


\section{Results}

In order to evaluate the effectiveness of the CET after two years, we conducted both a $2 \times 2 \times 2($ Group $\times$ Time $\times$ Sex) multivariate analysis of variance (MANOVA) and univariate analyses of variance (ANOVA). The variable sex was considered in both analyses as a "within-factor" since the data originated from couples. As several scores of the intervention and control groups already differed at the pre-test, we further computed ANCOVAs where the value of the pretest was treated as a covariate. Analyses were computed for the six subscales of the INCOPE as well as for the different coping strategies. For further statistical validation of our findings, the effect size was calculated according to the following formula: $M 1-M_{\mathrm{k}} / S D$ pooled, with $M_{1}$ representing the average change that occurred in the intervention group from the time of the pre-measurement and $\mathrm{M}_{\mathrm{k}}$ that of the control group during each measurement period.

The MANOVA for the subscales revealed a significant Time $\times$ Group effect, $F(6,132)=2.5, p<.03$, indicating that the intervention group improved significantly with regard to coping abilities. The ANOVAs show that the total score of the INCOPE improved significantly, $F(1,139)=$ $13.2, p<.001$, ANCOVA $F(1,139)=4.1, p<.05$. Positive changes were observed in the subscales rumination, $F(1,139)=7.5, p<.001$, ANCOVA not significant; positive self-verbalization, $F(1,139)=11.9, p<.001$, ANCOVA $F(1,138)=3.01, p<.08$; problem-solving, $F(1$, $139)=7.8, p<.01$, ANCOVA $F(1,137)=3.5, p<.06$, as well as marginally within the subscale for expression of negative emotions, $F(1,139)=3.5, p<.07$, ANCOVA not significant. There were no significant changes with regard to the subscales negative palliation (smoking, alcohol consumption, drugs etc.) and avoidance/withdrawal. Sex differences were significant for nearly all the subscales, with the exception of avoidance/withdrawal. Women showed higher scores in rumination, $F(6,132)=40.0, p<.001$, positive self-verbalization, $F(6,132)=11.9, p<.001$, problem-solving, $F(6,132)=17.9, p<.001$, expression of negative emotions, $F(6,132)=80.7, p<.001$, and negative palliation, $F(6,132)=4.2, p<.05$ (see Table 2$)$.

The effect sizes for the subscales were moderate for the women, but were rather weak for the men. The highest effect was found in female subjects for the subscale problem-solving $(d=.54)$, followed by rumination $(d=-.48)$, expression of negative emotions $(d=-.41)$ and positive self-verbalization $(d=.30)$. Positive self-verbalization revealed a small effect size for the men $(d=.26)$. All other subscales revealed no substantial change within the twoyear time period after the training. The effect sizes for the total score of the INCOPE were $d=.67$ for women and $d=.23$ for men.

In order to investigate changes within the different coping strategies such as active influence, reframing, seeking social support, etc., we conducted further analyses of variance with all the items of the INCOPE. The functional and dysfunctional coping strategies were split according to factor analysis, which took into consideration two forced factors and theoretical assumptions. This procedure allowed us to highlight which coping strategies accounted

Table 2

Means and standard deviation of the six coping subscales in the intervention and control groups at the beginning and after two years

\begin{tabular}{|c|c|c|c|c|c|c|c|c|}
\hline \multirow[b]{3}{*}{ Intervention group ( $N=73$ couples $)$} & \multicolumn{4}{|c|}{ Women } & \multicolumn{4}{|c|}{ Men } \\
\hline & \multicolumn{2}{|c|}{ Pre } & \multicolumn{2}{|c|}{ after 2 years } & \multicolumn{2}{|c|}{ Pre } & \multicolumn{2}{|c|}{ after 2 years } \\
\hline & $M$ & $S D$ & $M$ & $S D$ & $M$ & $S D$ & $M$ & $S D$ \\
\hline Rumination & 3.72 & .63 & 3.32 & .66 & 3.25 & .64 & 2.98 & .54 \\
\hline Positive self-verbalization & 3.14 & .77 & 3.43 & .82 & 2.86 & .74 & 3.16 & .73 \\
\hline Problem-solving & 3.09 & .53 & 3.32 & .58 & 2.92 & .45 & 3.05 & .48 \\
\hline Expression of negative emotions & 2.80 & .66 & 2.40 & .58 & 2.20 & .53 & 1.96 & .58 \\
\hline Negative palliation & 2.50 & .78 & 2.32 & .70 & 2.31 & .73 & 2.20 & .60 \\
\hline Avoidance/withdrawal & 2.48 & .97 & 2.32 & .88 & 2.68 & 1.03 & 2.53 & .87 \\
\hline Total score (INCOPE) & 3.01 & .38 & 3.28 & .42 & 3.17 & .32 & 3.35 & .32 \\
\hline \multicolumn{9}{|l|}{ Control group ( $N=70$ couples $)$} \\
\hline Rumination & 3.29 & .63 & 3.14 & .59 & 2.94 & .60 & 2.75 & .52 \\
\hline Positive self-verbalization & 3.30 & .78 & 3.34 & .83 & 3.00 & .89 & 3.07 & 1.02 \\
\hline Problem-solving & 3.33 & .49 & 3.30 & .60 & 3.07 & .48 & 3.11 & .60 \\
\hline Expression of negative emotions & 2.44 & .48 & 2.29 & .59 & 2.11 & .57 & 1.88 & .53 \\
\hline Negative palliation & 2.31 & .64 & 2.26 & .67 & 2.26 & .65 & 2.10 & .59 \\
\hline Avoidance/withdrawal & 2.47 & .64 & 2.56 & .90 & 2.61 & .84 & 2.56 & .83 \\
\hline Total score (INCOPE) & 3.26 & .31 & 3.31 & .27 & 3.32 & .35 & 3.43 & .30 \\
\hline
\end{tabular}


for significant changes in regard to the six factors reported above.

\section{Intervention effects of functional and dysfunctional coping after two years}

\section{Functional individual Coping}

The MANOVA for functional individual coping strategies revealed significant effects for time, $F(6,129)=3.95, p<$ .001 and for sex, $F(6,129)=11.27, p<.001$. All other effects were non-significant. However, the total score of the INCOPE increased significantly within the intervention group when compared with the control group, $F(1,139)$ $=9.49, p<.002$, ANCOVA $F(1,137)=3.42, p<.07$. Significant Time $\times$ Group effects were found in the computed univariate analyses of variance. Thus active influence, $F(1,138)=8.91, p<.003$, ANCOVA $F(1,136)=5.40$, $p<.03$, positive self-verbalization, $F(1,139)=5.25, p<$ .03 , ANCOVA not significant, and information seeking, $F(1,139)=5.89, p<.02$, ANCOVA not significant, increased in frequency of application even two years after the training. An interpretation that positive coping strategies can be induced in subjects participating in the training (CET) and that these coping strategies remain relatively stable over a two-year period would seem a valid conclusion. Despite the fact that the effects are weaker after a two-year period, we nevertheless find an improvement in important coping skills, particularly in more active types of coping (see Table 3 ).

\section{Dysfunctional individual coping}

After two years, the MANOVA also showed a significant effect for time, $F(10,121)=11.85, p<.001$, and sex, $F(10$, $121)=13.48, p<.001$ as well as for group, $F(10,121)=$ $2.31, p<.02$. All other effects were non-significant.

The ANOVAs (Time $\times$ Group interaction) and ANCOVAs revealed significant effects for the following subscales: rumination, $F(1,138)=4.90, p<.03$, ANCOVA not significant, self-blaming, $F(1,138)=4.43, p<.04$, ANCOVA not significant and negative emotional expression, $F(1,138)=4.24, p<.05$, ANCOVA $F(1,136)=2.97$, $p<.09$ as well as a marginal effect for blaming the partner, $F(1,138)=3.33, p<.07$, ANCOVA not significant. These results reveal that the effects of dysfunctional coping strategies were reduced and that after this period subjects resumed applying negative coping strategies more frequently (relapse of dysfunctional coping strategies) (see Table 4).

\section{Discussion}

In this article we presented a coping-focused prevention program (CET) that is part of the Couples Coping Enhancement Training (CCET) developed by Bodenmann (1997). Whereas the CET addresses only the enhancement of individual coping skills and is also applied in the context of general mental health prevention, the CCET is an

Table 3

Means and standard deviations of functional coping strategies at the beginning and after two years

\begin{tabular}{|c|c|c|c|c|c|c|c|c|}
\hline \multirow{3}{*}{$\begin{array}{l}\text { Intervention group } \\
(N=73 \text { couples })\end{array}$} & \multicolumn{4}{|c|}{ Women } & \multicolumn{4}{|c|}{ Men } \\
\hline & \multicolumn{2}{|c|}{ Pre } & \multicolumn{2}{|c|}{ Follow-up after two years } & \multicolumn{2}{|c|}{ Pre } & \multicolumn{2}{|c|}{ Follow-up after two years } \\
\hline & $M$ & $S D$ & $M$ & $S D$ & $M$ & $S D$ & $M$ & $S D$ \\
\hline Palliation & 2.71 & .88 & 2.95 & .88 & 2.32 & .83 & 2.50 & .72 \\
\hline Reframing & 2.92 & 1.00 & 3.11 & 1.06 & 2.85 & .79 & 3.01 & .86 \\
\hline Active influence & 3.51 & .94 & 3.93 & .82 & 3.56 & .80 & 3.88 & .75 \\
\hline Positive self-verbalization & 3.29 & .71 & 3.54 & .73 & 3.15 & .73 & 3.30 & .64 \\
\hline Information seeking & 3.81 & .88 & 4.10 & .84 & 3.82 & .81 & 3.95 & .80 \\
\hline Seeking social support & 2.82 & .69 & 3.08 & .78 & 2.40 & .74 & 2.58 & .78 \\
\hline Total score (INCOPE) & 2.91 & .51 & 3.17 & .58 & 2.85 & .40 & 3.03 & .41 \\
\hline \multicolumn{9}{|l|}{$\begin{array}{l}\text { Control group } \\
(N=70 \text { couples })\end{array}$} \\
\hline Palliation & 3.02 & .89 & 3.04 & .88 & 2.45 & .90 & 2.59 & 1.05 \\
\hline Reframing & 2.99 & .97 & 3.03 & .97 & 2.96 & 1.04 & 3.00 & 1.18 \\
\hline Active influence & 3.66 & .72 & 3.70 & .81 & 3.73 & .88 & 3.79 & .76 \\
\hline Positive self-verbalization & 3.54 & .71 & 3.62 & .67 & 3.41 & .72 & 3.31 & .83 \\
\hline Information seeking & 4.20 & .71 & 3.93 & .81 & 3.94 & .74 & 4.10 & .90 \\
\hline Seeking social support & 2.71 & .78 & 2.86 & .83 & 2.48 & .78 & 2.51 & .75 \\
\hline Total score (INCOPE) & 3.17 & .43 & 3.18 & .53 & 3.05 & .49 & 3.09 & .59 \\
\hline
\end{tabular}


Table 4

Means and standard deviations for dysfunctional coping strategies at the beginning and after two years

\begin{tabular}{|c|c|c|c|c|c|c|c|c|}
\hline \multirow{3}{*}{$\begin{array}{l}\text { Intervention group } \\
(N=73 \text { couples })\end{array}$} & \multicolumn{4}{|c|}{ Women } & \multicolumn{4}{|c|}{ Men } \\
\hline & \multicolumn{2}{|c|}{ Pre } & \multicolumn{2}{|c|}{$\begin{array}{c}\text { Follow-up after } \\
\text { two years }\end{array}$} & \multicolumn{2}{|c|}{ Pre } & \multicolumn{2}{|c|}{$\begin{array}{c}\text { Follow-up after } \\
\text { two years }\end{array}$} \\
\hline & $M$ & $S D$ & $M$ & $S D$ & $M$ & $S D$ & $M$ & $S D$ \\
\hline Comparison with others & 2.75 & 1.04 & 2.73 & .84 & 2.51 & 1.02 & 2.53 & .87 \\
\hline Information suppression & 2.10 & .97 & 2.30 & .91 & 2.65 & .95 & 2.71 & .89 \\
\hline Negative palliation & 2.37 & .94 & 2.12 & .88 & 2.21 & .83 & 2.03 & .79 \\
\hline Emotion-focused information seeking & 3.40 & 1.00 & 3.51 & .96 & 2.78 & 1.00 & 2.88 & 1.01 \\
\hline Blaming others & 2.81 & .88 & 2.40 & .85 & 2.31 & .74 & 2.03 & .75 \\
\hline Self-blaming & 3.10 & .84 & 2.64 & .89 & 2.74 & .91 & 2.22 & .90 \\
\hline Blaming the partner & 2.71 & .95 & 2.33 & .78 & 2.11 & .81 & 1.81 & .76 \\
\hline Negative emotional expression & 2.89 & .95 & 2.47 & .71 & 2.19 & .86 & 2.05 & .83 \\
\hline Avoidance & 2.48 & .97 & 2.32 & .88 & 2.68 & 1.03 & 2.53 & .87 \\
\hline Rumination & 4.14 & .98 & 3.55 & 1.00 & 3.38 & 1.02 & 3.08 & .88 \\
\hline Total score & 2.90 & .41 & 2.62 & .44 & 2.51 & .41 & 2.32 & .45 \\
\hline \multicolumn{9}{|l|}{$\begin{array}{l}\text { Control group } \\
(N=70 \text { couples })\end{array}$} \\
\hline Comparison with others & 2.60 & .86 & 2.58 & .90 & 2.37 & .92 & 2.35 & .96 \\
\hline Information suppression & 2.61 & 1.08 & 2.71 & 1.03 & 2.91 & 1.13 & 2.99 & 1.07 \\
\hline Negative palliation & 2.16 & .80 & 2.10 & .76 & 2.22 & .77 & 1.98 & .73 \\
\hline Emotion-focused information seeking & 3.49 & 1.01 & 3.40 & 1.05 & 2.80 & 1.02 & 2.93 & 1.07 \\
\hline Blaming others & 2.56 & .73 & 2.20 & .81 & 2.23 & .77 & 1.82 & .77 \\
\hline Self-blaming & 2.79 & .83 & 2.55 & .81 & 2.32 & .87 & 1.97 & .75 \\
\hline Blaming the partner & 2.24 & .69 & 2.19 & .71 & 1.88 & .72 & 1.65 & .71 \\
\hline Negative emotional expression & 2.56 & .83 & 2.49 & .80 & 2.20 & .80 & 2.15 & .76 \\
\hline Avoidance & 2.47 & .63 & 2.56 & .89 & 2.58 & .83 & 2.54 & .82 \\
\hline Rumination & 3.56 & .96 & 3.36 & .95 & 3.10 & .96 & 2.94 & .93 \\
\hline Total score & 2.66 & .37 & 2.55 & .44 & 2.41 & .42 & 2.23 & .42 \\
\hline
\end{tabular}

approach oriented toward couples. In addition to the components of the CET, this approach also teaches dyadic coping skills and communication features.

The goal of this article was to evaluate whether the individual-oriented aspect of the training, the CET, is effective in improving individual coping abilities. In order to research this issue, data from 286 subjects (143 couples) were collected over a period of two years. 73 couples formed the intervention group and 70 couples made up the control group.

The training (CET) focuses on three main components: a) the avoidance of unnecessary stress, b) the expansion of one's own hedonistic repertoire (pleasant activities) and, c) the improvement of matching appraisals and situation-appropriate coping strategies.

Our results reveal that the training is effective in increasing the general use of more adequate coping strategies over a period of two years. Participants in the training utilized functional strategies such as positive self-verbalization and active problem-solving more frequently, whereas negative coping behaviors were reduced (not significantly in the ANCOVAs). Our analyses re- vealed that women showed more substantial effects than did men in utilizing functional coping strategies whereas dysfunctional coping seemed to be somewhat less influenced by our training. Compared to the results of other studies of coping enhancement programs for which an average effect size $d=.20$ and .50 has been found (see Bamberg \& Busch, 1996), our effects seem encouraging. Kaluza (1997) reported in his meta-analysis effect sizes of $d=.36$ for coping improvement and $d=.02$ for an enhancement of stress appraisals after the implementation of coping enhancement programs, results that are less significant than those found in our approach. Despite the promising findings of our study, we found that the effects of the CET were less satisfying after two years than they were at the follow-up after one year (see Bodenmann, Perrez, et al., 2001). After one year, both men and women showed a significant improvement in coping abilities, which manifested as an increase in functional coping strategies and a reduction of dysfunctional coping strategies. Thus, one main question necessitating consideration is how the results of a preventive approach can be further improved and, above all, how functional coping can be 
maintained and dysfunctional coping reduced or eliminated over a long-term basis. As men seem to loose their learned skills more quickly than do women, it would also seem necessary to target this group more consistently, testing possibilities as to how to encourage men to continue to display adequate coping behavior.

As it is our assumption that the long-term use of functional coping strategies is necessary to foster subjective well-being, it is vital to continue to investigate how a commitment to these strategies can be reinforced. The more the participants attempt to use these coping strategies in their daily lives, the greater the probability will be that they will use them successfully and will avoid repeating prior negative strategies. Consequently, it is of utmost importance that the participants in the training be strongly encouraged to practice the competencies at home (in the form of homework during the training) and then to use the strategies as often as possible in their daily lives in order to become reinforced in their practice. Theoretical and motivational techniques regarding this are available and are encouraged for one-time preventive interventions (such as in the CET) in order to help the participants retain what they have learned over a long-term period. Our data suggest that successful, long-term use is more a question of proper motivation than it is of the competencies themselves.

Because this study focuses only on changes in coping, it would be interesting to compare these changes with improvements in daily life experience such as physical and psychological well-being, professional performance and life satisfaction. To answer these questions it will be crucial to ascertain the usefulness and effectiveness of stress prevention programs in the field of health care. Thus, it is our opinion that further studies on the impact of stress prevention programs are needed.

\section{References}

Bamberg, E., \& Busch, C. (1996). Betriebliche Gesundheitsförderung durch Stressmanagementtraining: Eine MetaAnalyse (quasi-)experimenteller Studien [Worksite health promotion by stress management training programs: A metaanalysis of experimental studies]. Zeitschrift für Arbeits- und Organisationspsychologie, 40, 127-137.

Beck, A. T., Rush, A. J., Shaw, B. F., \& Emery, G. (1979). Cognitive therapy of depression. New York: Guilford.

Bodenmann, G. (1997). Can divorce be reduced by enhancing the coping skills of couples? Journal of Divorce and Remarriage, 27, 177-194.

Bodenmann, G. (2000). Stress und Coping bei Paaren [Stress and coping in couples]. Göttingen: Hogrefe.
Bodenmann, G., Charvoz, L., Cina, A., \& Widmer, K. (2001). Prevention of marital distress by enhancing the coping skills of couples: 1-year follow-up-study. Swiss Journal of Psychology, 60, 3-10.

Bodenmann, G., Perrez, M., Cina, A., \& Widmer, K. (2001). Verbesserung der individuellen Stressbewältigung im Rahmen des Freiburger Stressbewältigungstrainings (FSPT): Ergebnisse einer 1-Jahres-Follow-up-Untersuchung [The improvement of individual coping skills with the Freiburger Stress-Präventions-Training (Couples Coping Enhancement Training): Results of a 1-year follow-up study]. Zeitschrift für Gesundheitspsychologie, 9, 2-12.

Canella, K. A. S. (1988). The effectiveness of stress coping interventions: A meta-analysis with methodological implications. Dissertation Abstracts International, 48, 1705A.

D’Zurilla, T. J., \& Goldfried, M. R. (1971). Problem-solving and behavior modification. Journal of Abnormal Psychology, 78, 107-126.

Jacobson, E. (1938). Progressive relaxation. Chicago: University Press.

Janke, W., Erdmann, G., \& Kallus, W. (Hrsg.). (1985). Stressverarbeitungsfragebogen $(S V F)$. Handanweisung [Coping with Stress Questionnaire]. Göttingen: Hogrefe.

Kaluza, G. (1997). Evaluation von Stressbewältigungstrainings in der primären Prävention - eine Meta-Analyse (quasi-) experimenteller Feldstudien [Evaluation of stress management training programs in primary prevention - A metaanalysis of (quasi-)experimental studies]. Zeitschrift für Gesundheitspsychologie, 3, 149-169.

Kanner, A. D., Coyne, J. C., Schaefer, C., \& Lazarus, R. S. (1981). Comparisons of two modes of stress measurement: Daily hassles and uplifts versus major life events. Journal of Behavioral Medicine, 4, 1-39.

Koppenhoefer, E. (1990). Therapie und Förderung genussvollen Erlebens und Handelns [Therapy and promotion of enjoyment]. In M. Zielke \& N. Mark (Hrsg.), Fortschritte der angewandten Verhaltensmedizin (S. 250-263). Berlin: Springer.

Lazarus, R. S. (1986). Puzzles in the study of daily stress. In R. K. Silbereisen, K. Eyferth \& G. Rudiger (Eds.), Development as action in context (pp. 39-53). Berlin: Springer.

Lazarus, R. S. (1993). Coping theory and research: Past, present, and future. Psychosomatic Medicine, 55, 234-247.

Lazarus, R. S., \& Folkman, S. (1984). Stress, appraisal, and coping. New York: Springer.

Lazarus, R. S., \& Launier, R. (1978). Stress-related transactions between person and environment. In L. A. Pervin \& M. Lewis (Eds.), Perspective in interactional psychology (pp. 287-327). New York: Plenum.

Maccoby, N., \& Solomon, D. S. (1981). Heart disease prevention. Community studies. In R. E. Rice \& W. J. Paisley (Eds.), Psychology and health (pp. 105-125). Beverly Hills: Sage.

Meichenbaum, D. H. (1991). Intervention bei Stress. Anwendung und Wirkung des Stressimpfungstrainings [Stress inoculation training]. Bern: Huber.

Nicholson, R. A., Duncan, D. F., Hawkins, W., Belcastro, P. A., \& Gold, R. (1988). Stress treatment: Two aspirins, fluids, and one more workshop. Professional Psychology: Research and Practice, 19, 637-641.

Swiss J Psychol 61 (4), 2002, ( Verlag Hans Huber, Bern 
Perrez, M., \& Reicherts, M. (1992). Stress, coping and health. A situation-behaviour-approach. Theory, methods, applications. Toronto: Hogrefe \& Huber.

Schröder, H. (1996). Psychologische Präventionsmöglichkeiten bei Stressbelastung. In H. Schröder \& K. Reschke (Hrsg.), Intervention zur Gesundheitsförderung für Klinik und Alltag [Health promotion in clinics and everyday life] (S. 7-26). Regensburg: Roderer.
Weiner, B. (1982). The emotional consequences of causal ascriptions. In M. S. Clark \& S. T. Fiske (Eds.), Affect and cognition (pp. 185-209). New York: Erlbaum.

Prof. Dr. Guy Bodenmann

University of Fribourg

Avenue de la gare 1

CH-1700 Fribourg

E-mail: joseguy.bodenmann@unifr.ch 